\title{
SIGNAL CONTROLLER \\ PEER-TO-PEER \\ COMMUNICATIONS
}

Using advanced controller features to improve operations

Matt Luker, P.E., PTOE Utah Department of Transportation 


\section{The Problem We're Trying to Solve}

- When signals are close together, they need to work together

- Time-base coordination sometimes isn't good enough

- Requires a fixed cycle length

- If not the coordinated phase, downstream signal can gap out before traffic can arrive from upstream signal

- Inefficient to coordinate very small groups of signals

- Adaptive control may also not be ideal

- Expensive and complicated (although P2P isn't exactly simple)

- Adapts to the last cycle or cycles, not to immediate demand 


\section{When Time-Base Coordination Isn't Ideal}
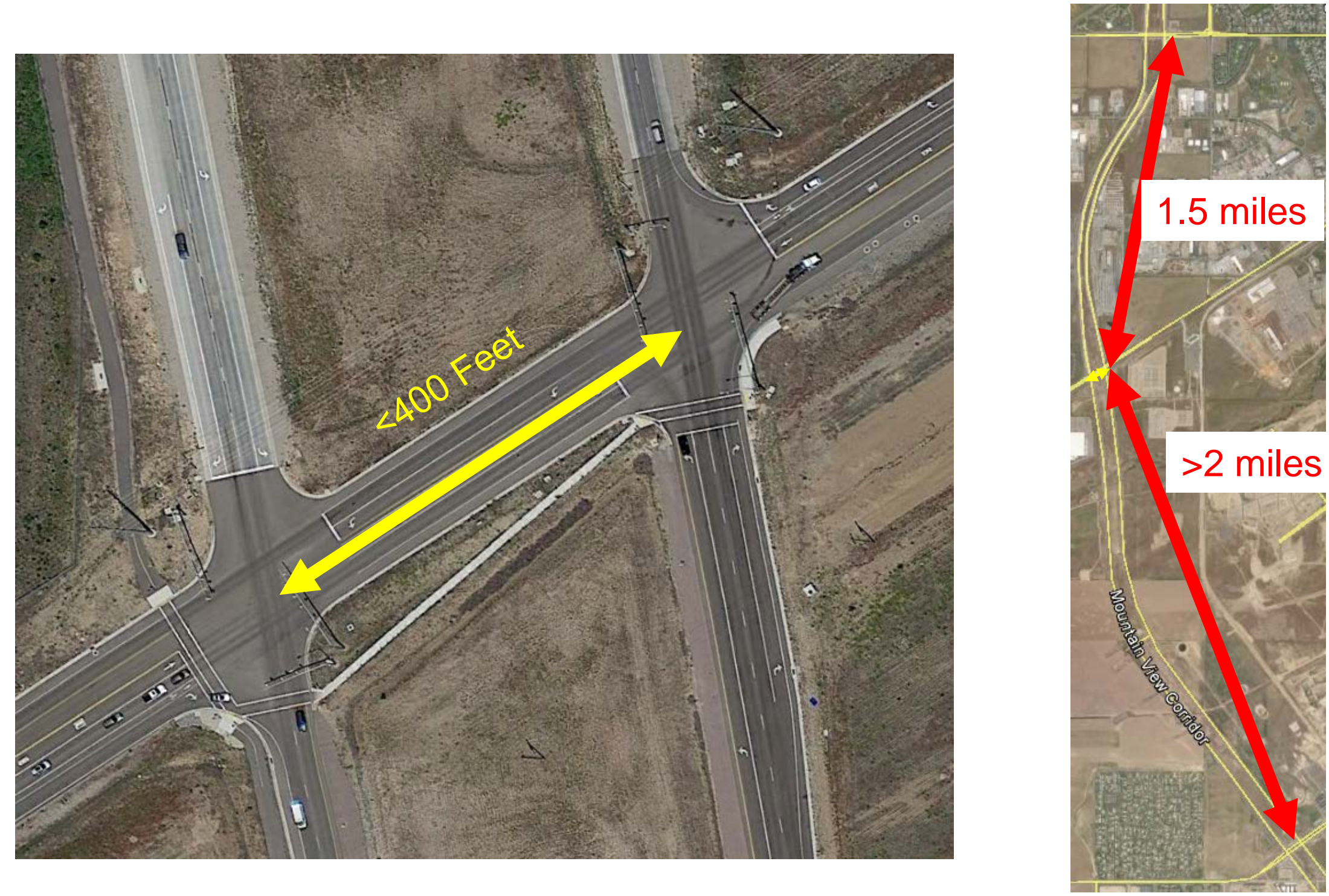


\section{Past Solutions}

- Use a single controller

- Some locations require more output channels than a single cabinet can provide, requiring two cabinets

- Legacy locations built before controllers had capability to handle two intersections

- Locations built with ease-of-maintenance in mind instead of operations

- Use custom-built interconnect logic

- Pray that you never have a knock-down
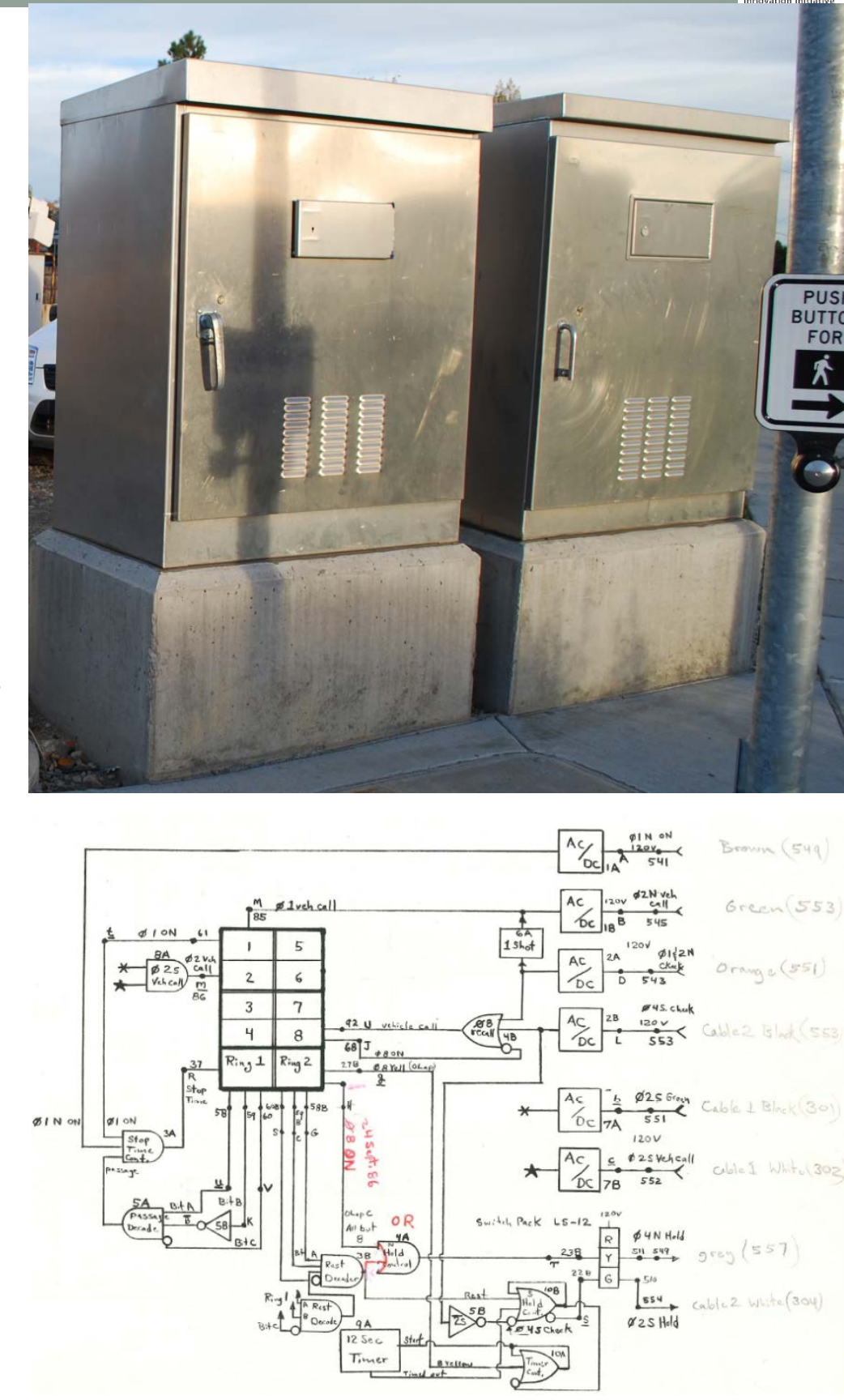


\section{New Solution}

- Use modern controllers with capability for built-in logic AND peer-to-peer communications
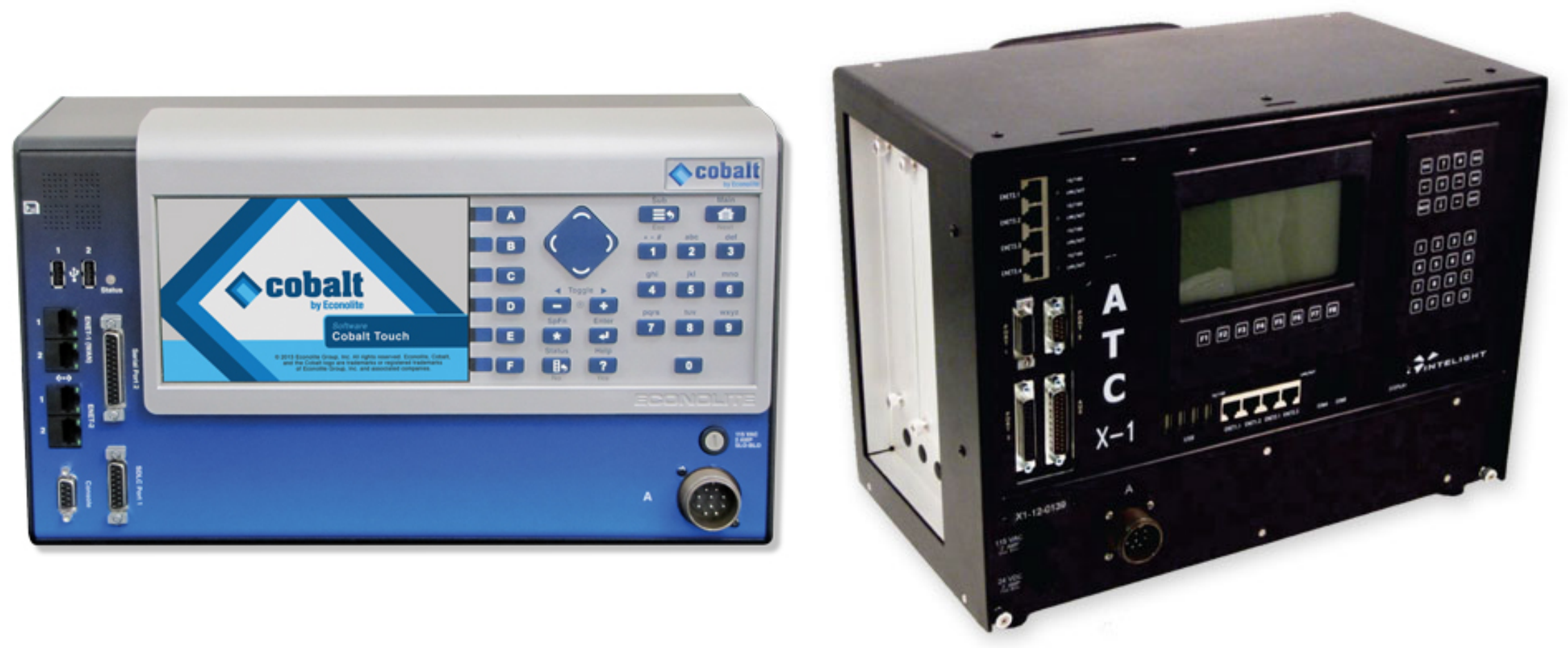


\section{Availability of These Features}

- UDOT has successfully used controllers from:

- Econolite (Cobalt controller/software)

- Intelight (MaxTime software)

- Siemens (NextPhase software, capabilities are limited by controller hardware)

- Other vendors may also offer similar features 


\section{No Standardization}

- All controllers in a P2P network must be from the same manufacturer.

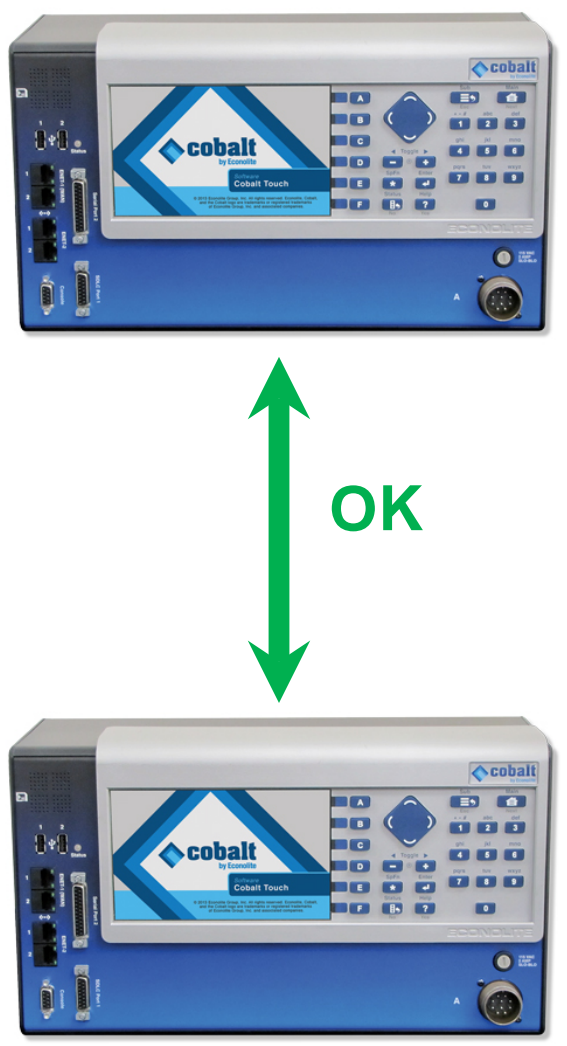

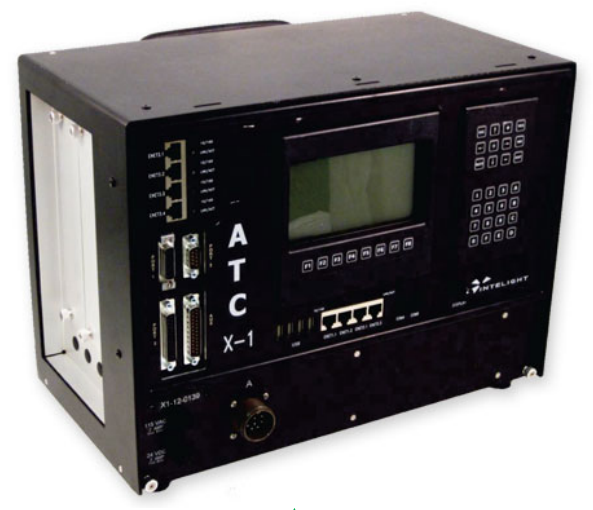

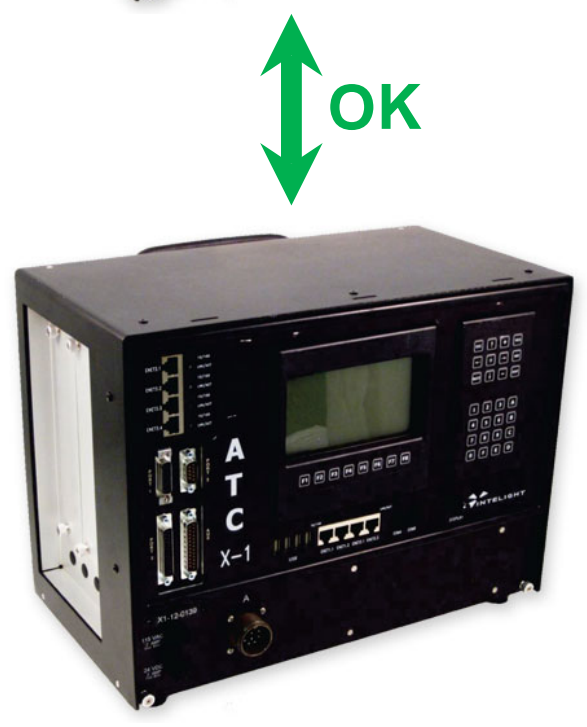

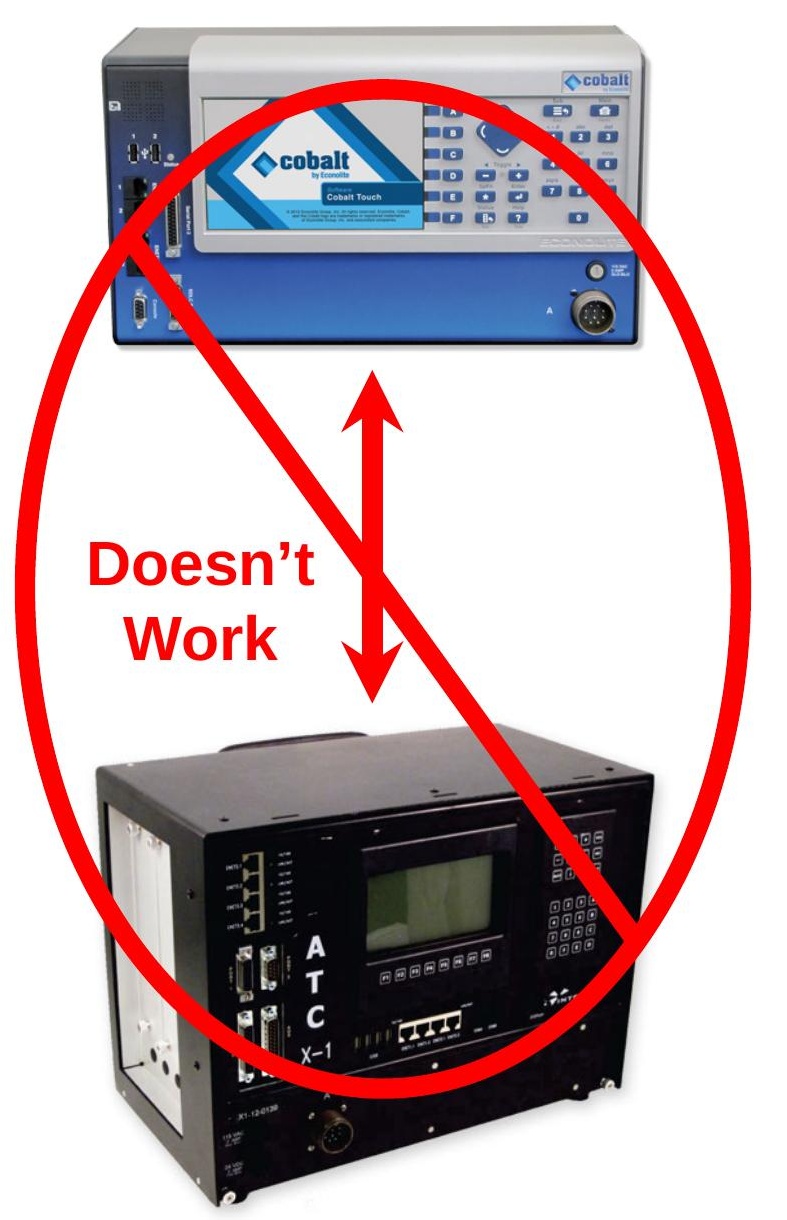




\section{P2P CASE STUDY}

Mountain View (SR-85) @ Daybreak Parkway

South Jordan, UT 


\section{Site Description}

-55mph Divided Highway

- Distance between $1^{\text {st }}$ and $2^{\text {nd }}$ stop-bar on cross-street is $\sim 370$ '

- Crashes

- Some drivers have blamed crashes on confusion between downstream/upstream signals

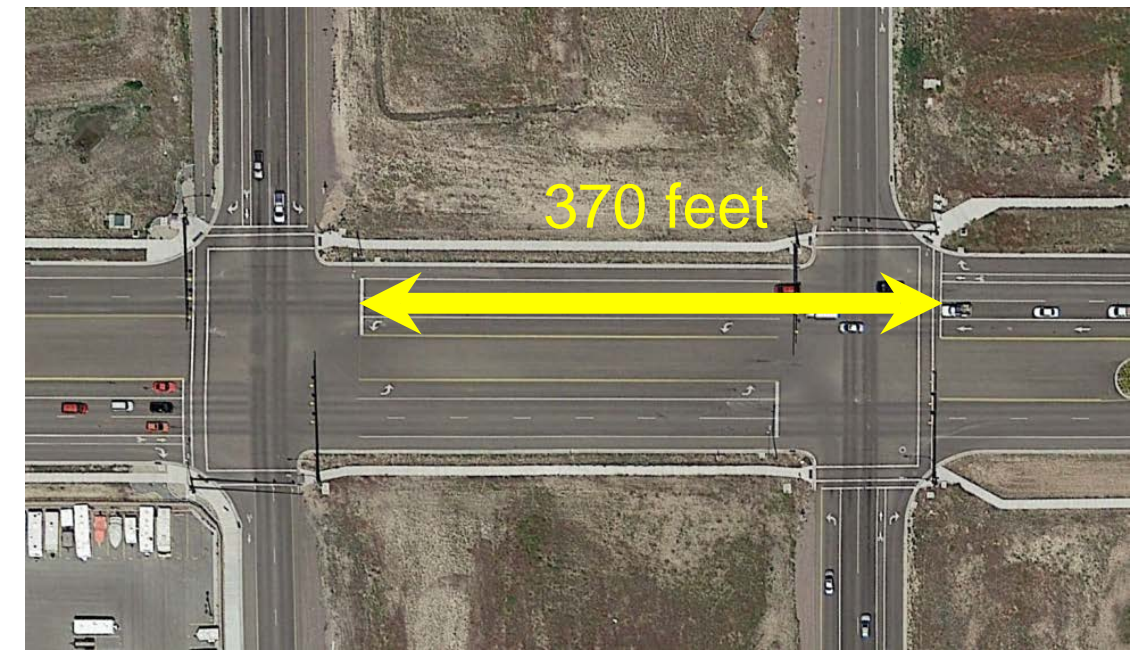

Mountain View runs $\sim N / S$ Daybreak Pkwy runs $\sim$ E/W 


\section{P2P Solution}

- Master/Slave

- Controller at NB side

(master) times all movements for both sides

- Controller at SB side (slave) times based on inputs from master essentially an auxiliary output unit

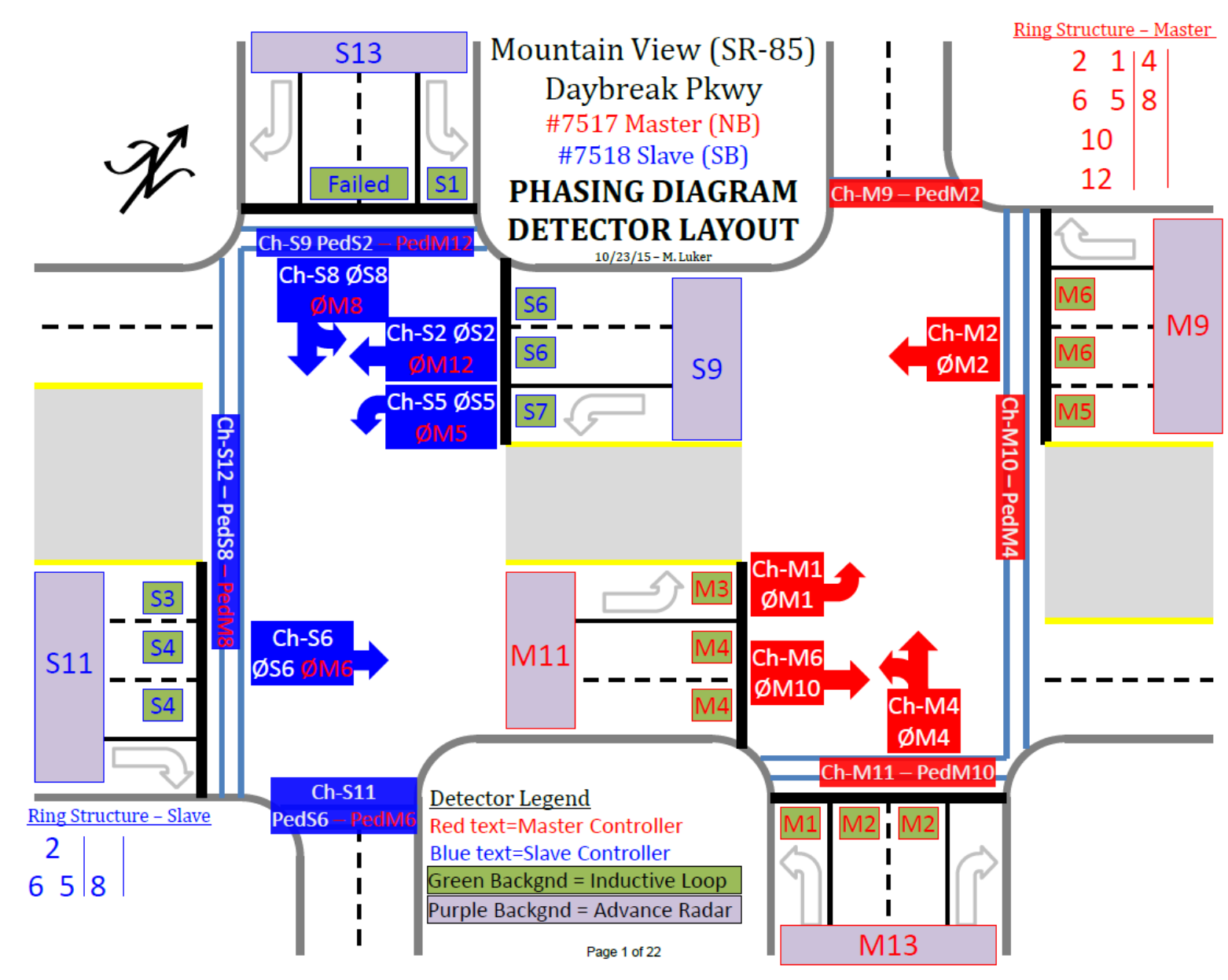




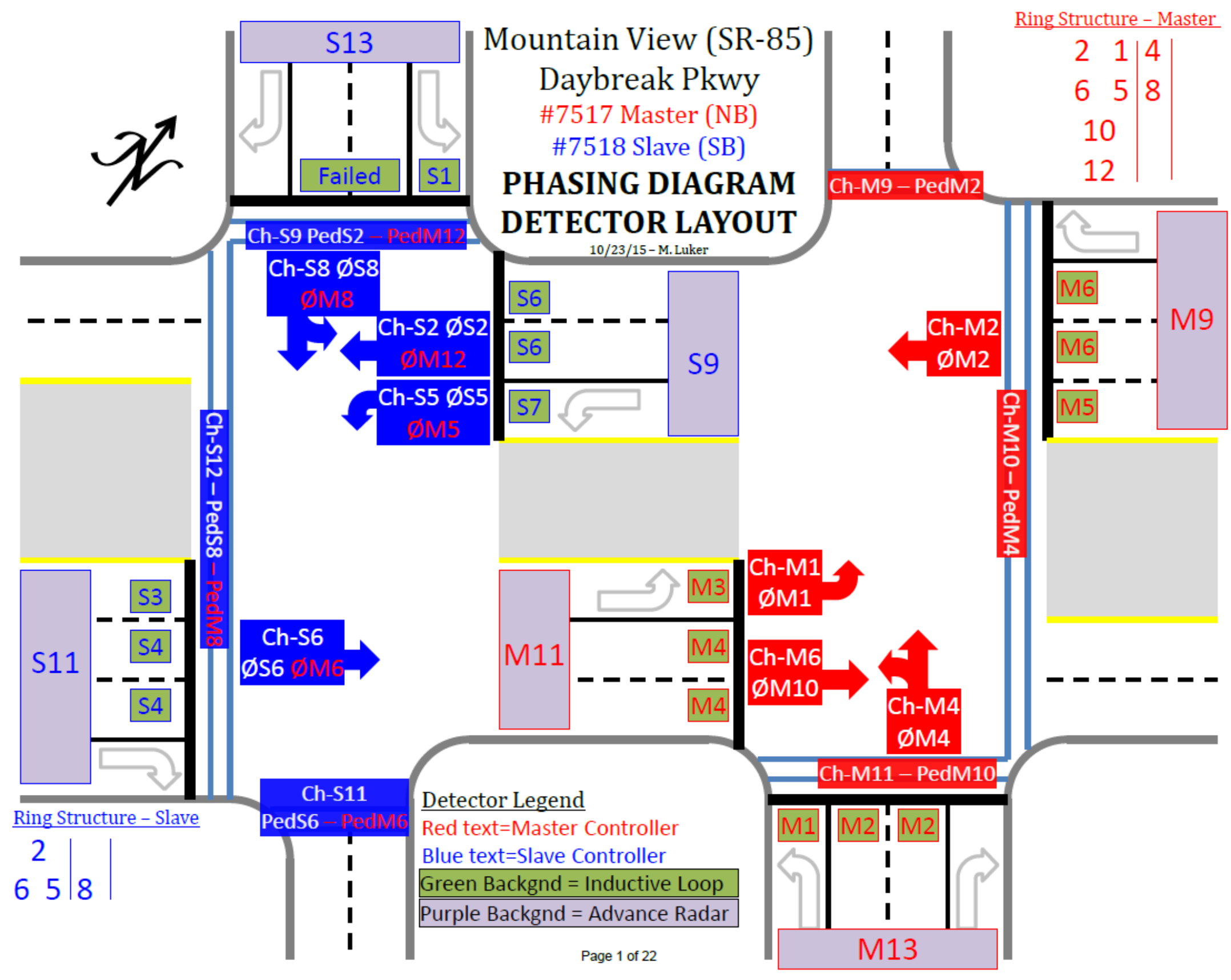




\section{Phasing}

- Operates as a lag/lag 3-phase diamond

Red $=$ Master Controller

Blue $=$ Slave Controller
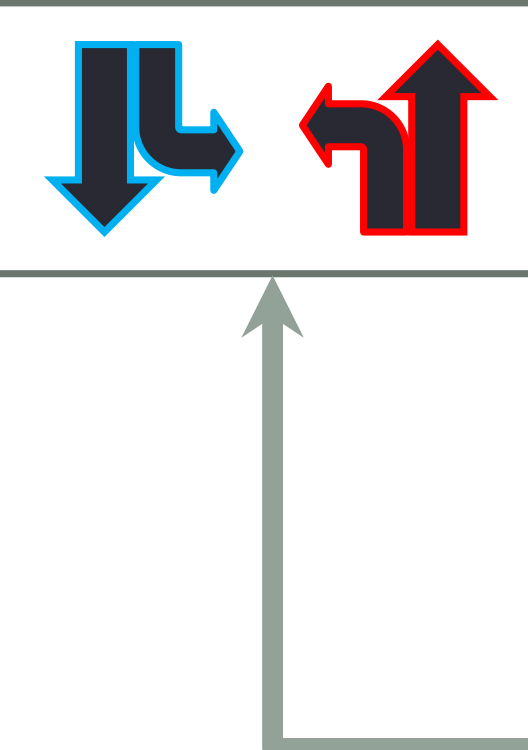

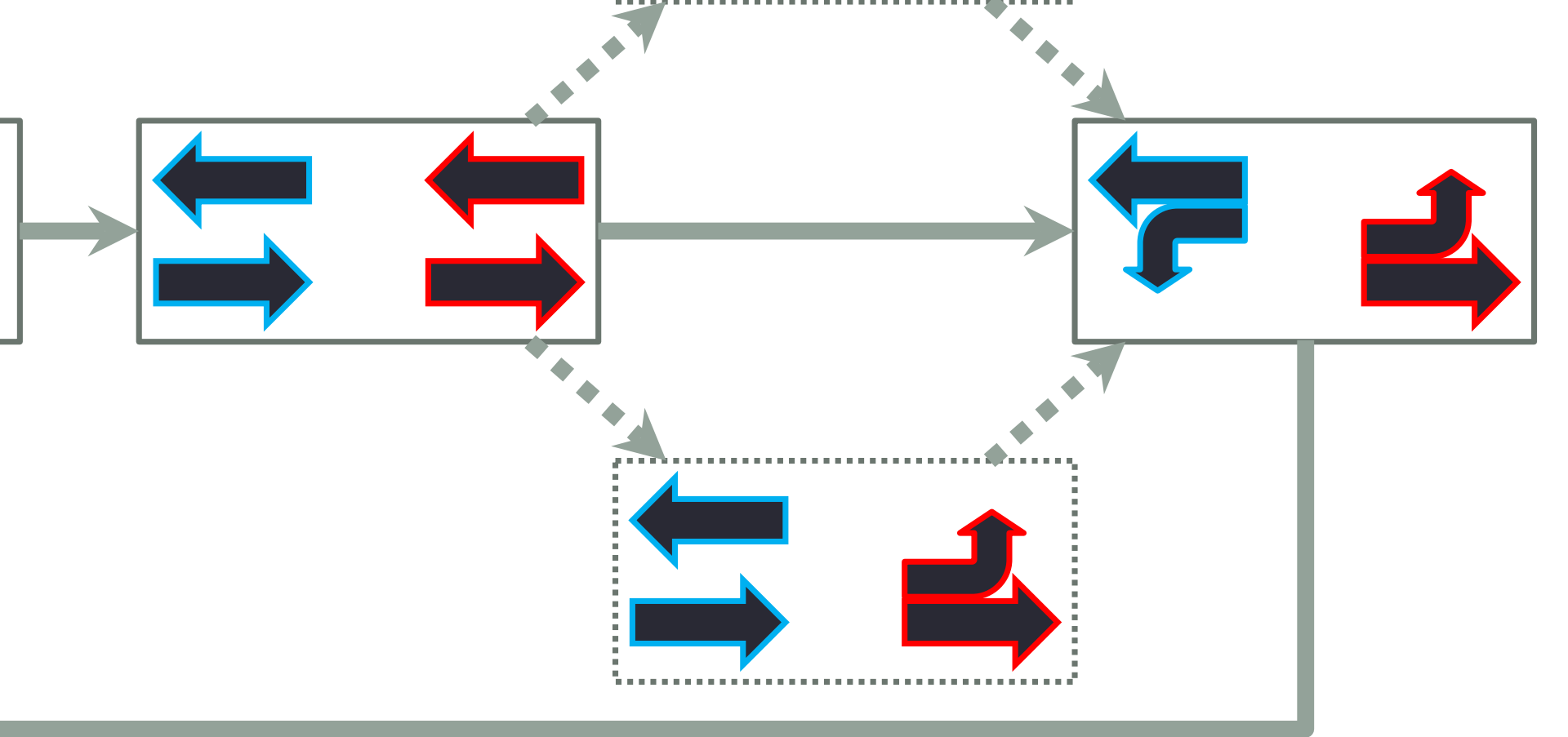




\section{How Master Controls Phases at Slave}

This programming is in the SLAVE controller's 'Logic Processor'

- When 'Master Control' is enabled and Comm is OK:

- IF controlling phase in MASTER is GREEN or NEXT:

- Call controlled phase in SLAVE

- Apply hold to controlled phase in SLAVE

- OTHERWISE

- Omit controlled phase in SLAVE

- Apply force-off to controlled phase in SLAVE 


\section{How Master Controls Peds at Slave}

This programming is in the SLAVE controller's 'Logic Processor'

- When 'Master Control' is enabled and Comm is OK:

- IF controlling ped in MASTER is timing WALK:

- Call controlled ped in SLAVE

- OTHERWISE

- Omit controlled ped in SLAVE 


\section{Detector Calls}

- Detectors are landed to local controller.

- Detectors at NB side are landed to Master and place calls directly.

- Detectors at SB side are landed to Slave and also place calls directly, but omits/calls/holds from Master can override

This programming is in the MASTER controller's 'Logic Processor'

- When 'Master Control' is enabled:

- IF there is an EXTEND or CHECK on controlled phase in SLAVE:

- Place call/extend to controlling phase in MASTER

Similar logic exists for ped calls from the Slave controller 


\section{Fail-Safes}

- Master controller CANNOT control duration of any of these intervals in the Slave controller:

- Minimum Green

- Ped 'Walk'

- Ped Clearance (Flashing 'Don't Walk')

- Yellow Change

- Red Clearance

- Master controller CAN override max green in Slave controller

- Master controller CANNOT override emergency vehicle preemption in Slave controller 


\section{Fail-Safes}

- If Master stops cycling or loses communications with Slave, Slave could become "stuck" (with all phases omitted except the phase that is timing)

- Slave contains logic that checks for following before applying omits/holds/force-offs:

- Master is timing any phase (this also checks communications)

- Master is not in flash

- (In Econolite controllers) "Slave Release" flag in Master is OFF (this flag allows intentional operation as two isolated intersections)

- (In Intelight controllers) There is no active call at the Slave that has gone unserved by the Master for more than 3 minutes 


\section{"Isolated" Operation}

- Sometimes it may be desirable to operate the two controllers separately

- Late at night

- Construction or incident closing certain movements

- Technician testing detection, etc.

- Custom logic includes ability to run "isolated" by time-ofday or manual override through central system

- Econolite logic: Flag can be activated in Master controller. When active, Slave does not respond to phase/ped control and Master does not respond to inputs from Slave detectors

- Intelight logic: Special sequence in Master that does not have barriers locking the rings together. Master still controls Slave but as an independent ring.

- For technician testing, just unplug the Cat-5 cable at either controller 


\section{Time-base Coordination with P2P}

- Sometimes TBC is desired at certain times of the day, such as to provide progression along an arterial.

- Coordination plans are entered into the Master controller only. Slave responds to Master controller the same whether Master is in "free" or "coord" mode

- P2P is still valuable during coordination:

- Both sides stay in step during pattern transitions

- Coord phases don't need to be on the movements between adjacent intersections - downstream signal will not gap out early

- If oversized peds are used, both sides stay in step while recovering 


\section{RESULTS}

Using Automated Signal Performance Metrics 


\section{Split Monitor}

\section{Controlling SB} phase 8 at Master

Shows gaps (green) and maxouts (red) throughout the day, based on detector calls from Slave

\section{Controlled SB} phase 8 at Slave

Always shows "force-off" (blue) because it is under control of Master
SR-85 NB (Mtn View) Daybreak Pkwy SIG\#7517 Phase 8

Friday, December 18, 2015 12:00 AM - Friday, December 18, 2015 11:59 PM

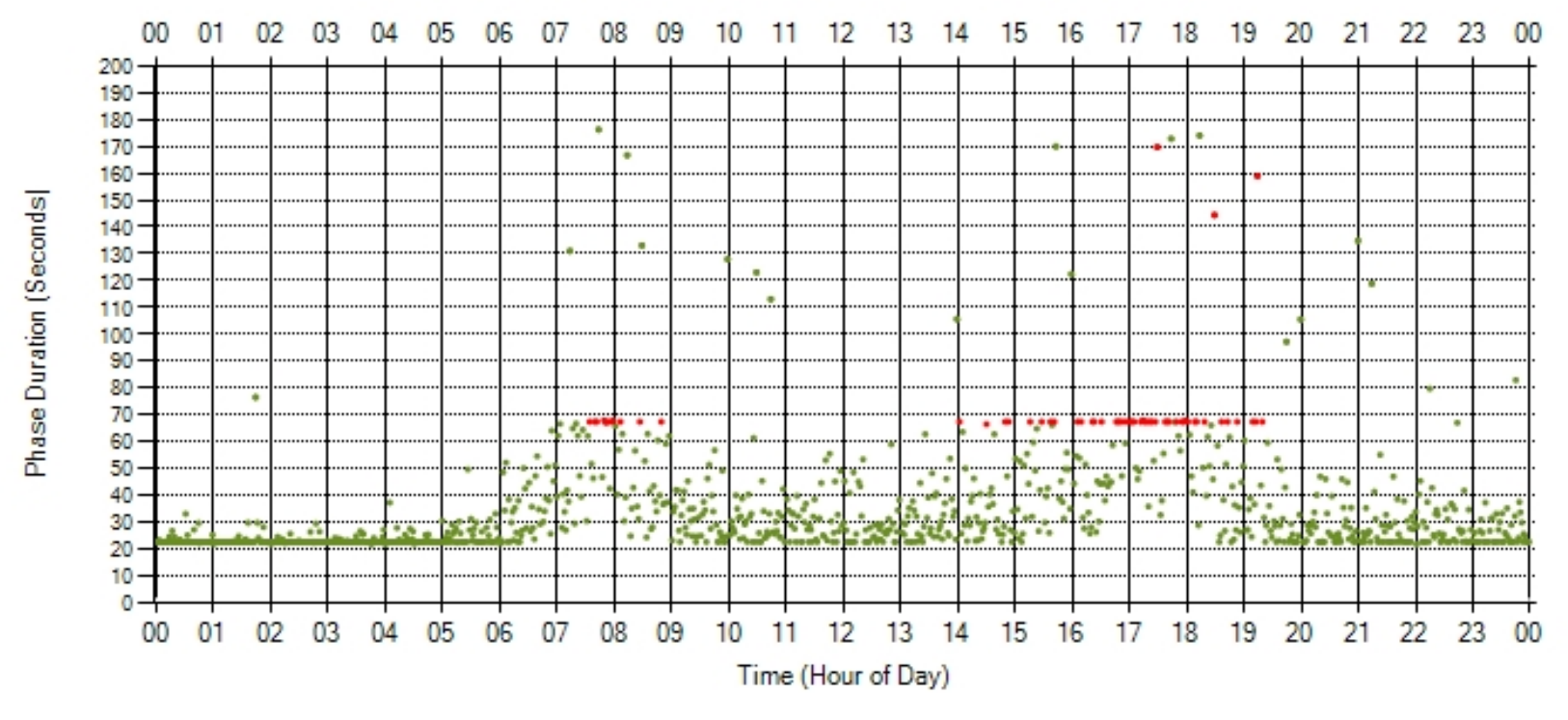

SR-85 SB (Mtn View) Daybreak Pkwy SIG $\# 7518$ Phase 8

Friday, December 18, 2015 12:00 AM - Friday. December 18, 2015 11:59 PM

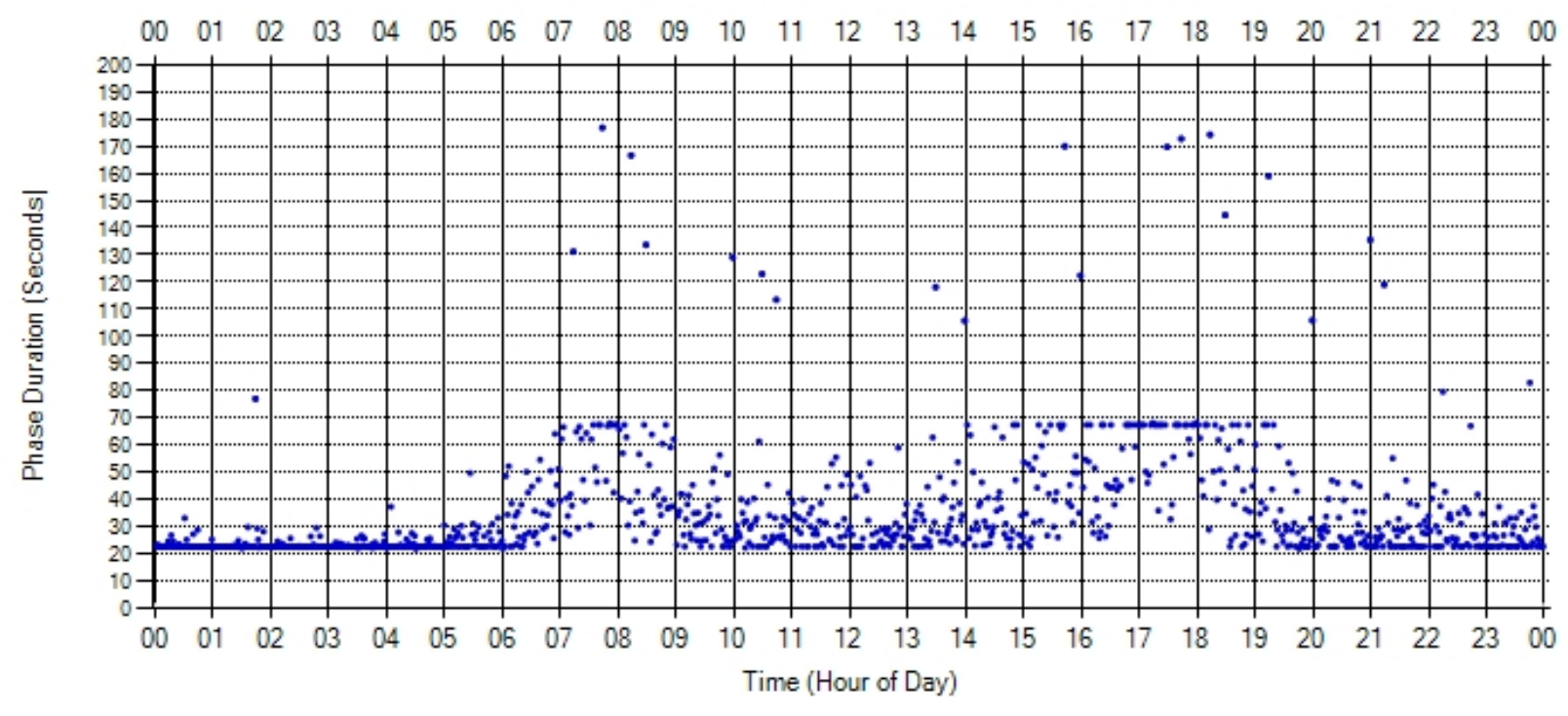


Purdue Coordination Diagram - WB at Slave (downstream)

Before: 2/18/15

Coordination in $A M$ and $P M$ peak

Full Day AoG: $60 \%$

After: 11/4/15

No time-base coordination

Full Day AoG: $76 \%$

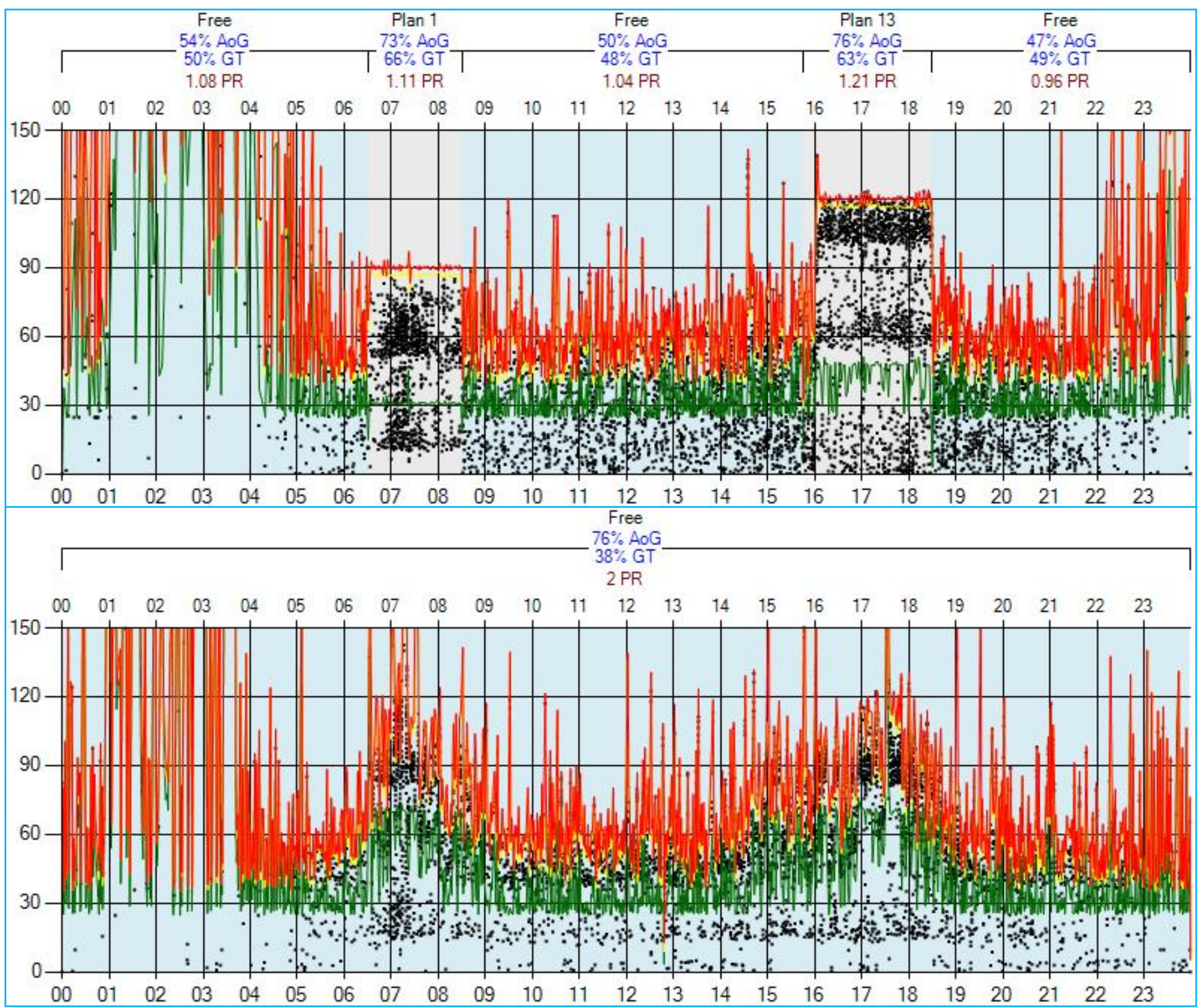




\section{Things to Consider}

- First implementation (in each controller type) takes many hours of research, development, and testing

- Subsequent implementations are easier, but still require extensive testing and documentation well beyond the level of a standard intersection

- Training required for maintenance and operations staff 


\section{QUESTIONS}

Matt Luker, P.E., PTOE

Utah Department of Transportation

mluker@utah.gov

801-887-3627 